\title{
Intrasitoplazmik Sperm Enjeksiyonu Sikluslarında Embriyo Transferinin Abdominal Ultrasonografi Kılavuzluğunda veya Ultrasonografi Kullanılmadan Yapılmasının Klinik Sonuçlarının Değerlendirilmesi
}

\author{
Işıl KASAPOĞLU ${ }^{1}$, Furkan ŞEN ${ }^{1}$, Esra ŞEN ${ }^{2}$, Berrin AVCI ${ }^{2}$, Gürkan UNCU ${ }^{1}$ \\ 1 Uludağ Üniversitesi Tıp Fakültesi, Kadın Hastalıkları ve Doğum Anabilim Dalı, Bursa. \\ 2 Uludağ Üniversitesi Tıp Fakültesi, Histoloji Embriyoloji Anabilim Dalı, Bursa.
}

\section{ÖZET}

Yardımlı üreme yöntemlerinde ovaryan stimülasyon ve embriyo kültüründeki büyük ilerlemelere rağmen embriyo transfer (ET) tekniklerindeki ilerlemeler sınırlı kalmıştır ve optimal ET tekniği konusunda fikir birliği bulunmamaktadır. Retrospektif olarak yürüttüğümüz çalışmamızda ET sırasında abdominal ultrasonografi kullanılmasının, ultrasonografi kullanılmadan klinik dokunma yöntemi ile ET yapılan olguların implantasyon ve klinik gebelik oranlarının karşılaştırılması hedeflenmiştir. Beşinci günde iyi kalitede tek embriyo transferleri transabdominal ultrasonografi ile (grup 1, n=47) ve klinik dokunma yöntemi ile yapılan (grup 2, $\mathrm{n}=46$ ) hastaların implantasyon ve klinik gebelik oranları karşılaştırıldı. Sonuçta gruplar arasında implantasyon oranları için anlamlı farklılık izlenmedi (sırası ile grup 1 de $\% 42.6$ ve grup 2 de \%34.8, $\mathrm{p}=0,44)$. Klinik gebelik oranları sırası ile grup 1 de $\% 36.2$ ve grup $2 \mathrm{de} \% 26.1$ idi $(\mathrm{p}=0,29)$. Transfer sonrası transvajinal ultrasonografi ile kontrol edilen hava kabarcığının fundusa olan mesafeleri ve endometrial kalınlıkları karşılaştırıldığında; iki grup arasında anlamlı fark gözlenmedi sirasiyla; $\mathrm{p}=0,25$ ve $. \mathrm{p}=0,83$.

Anahtar Kelimeler: Intrasitoplazmik sperm enjeksiyonu. Embriyo transferi tekniği. Transabdominal ultrasonografi. İmplantasyon. Klinik gebelik.

Evaluation of The Clinical Outcomes of Embryo Transfer in Intracytoplasmic Sperm Injection Cycles with Guidance of Abdominal Ultrasonography or without Using Ultrasonography

\begin{abstract}
Despite the great development in ovarian stimulation and embryo culture in assisted reproductive techniques, progress in embryo transfer (ET) techniques remains limited and there is no consensus for optimal ET technique. In this retrospective study, we aimed to compare the implantation and clinical pregnancy rates for patients with two different transfer methods. Implantation and clinical pregnancy rates of day five, good quality, single transfered embryos were compared for transabdominal ultrasonography guidance (group $1, n=47$ ) and for clinical touch method (group 2, $\mathrm{n}=46$ ). There were no significant difference for implantation rates between the groups (42.6\% in group 1 and $34.8 \%$ in group 2, respectively, $\mathrm{p}=0.44$ ). Also clinical pregnancy rates were not different between groups; $36.2 \%$ for group 1 and $26.1 \%$ for group $2(p=0.29)$. When the distance between the uterus fundus and air bubbles and endometrial thickness during the embryo transfer controlled by transvaginal ultrasonography after transfer are compared; there were no significant difference between the two groups, respectively $\mathrm{p}=$ 0.25 and $\mathrm{p}=0,83$.
\end{abstract}

Key Words: Intracytoplasmic sperm injection. Embryo transfer technique. Transabdominal ultrasound. İmplantation. Clinical pregnancy.

Geliş Tarihi: 18 Nisan 2018

Kabul Tarihi: 06 Temmuz 2018

Dr. Işıl KASAPOĞLU

Uludağ Üniversitesi Tıp Fakültesi

Kadın Hastalıkları ve Doğum ABD

Tel.: 05305455848

E-posta: kasapogluisil@hotmail.com
Invitro fertilizasyon siklusları temel olarak 3 klinik basamaktan oluşmaktadır. $\mathrm{Bu}$ basamaklar; kontrollü ovaryan hiperstimülasyon $(\mathrm{KOH})$, oositlerin toplanması ve son olarak da elde edilen embriyonun endometriuma transferidir (ET). Günümüze kadar yardımla üreme yöntemlerinin (YÜT) iyileştirilmesi amacı ile ilgili yapılmış olan çalışmaların çoğu $\mathrm{KOH}$ protokolleri, elde edilen oosit ve embriyolar üzerine yoğunlaşmıştır ${ }^{1}$. 
Embriyo transferi ve implantasyon, IVF sikluslarının en önemli basamaklarındandır. Embriyo transferi sonrası implantasyon süreci günümüzde halen tam olarak aydınlatılamamış kompleks bir süreçtir ${ }^{2,3}$. Yardımla üreme yöntemlerinin kullanıldığı sikluslarda embriyo transferi (ET) sonrasi implantasyonun temel belirleyicisi embriyo kalitesi ve endometriumun reseptivitesi olmakla beraber ET tekniği de implantasyonu etkileyebilmektedir ${ }^{4}$. İmplantasyon ile ilgili çalışmaların çoğunda endometrial reseptivite değerlendirilmiş ancak ET teknikleri ile ilgili çalışma sayısı sınırlı kalmıştır ${ }^{5}$. Embriyo tekniklerindeki iyileştirme ile implantasyon ve fertilite tedavi yöntemleri başarı oranlar1 arttırılabilir 6 .

Embriyo transferinin amacı embriyoların endometrial kaviteye en uygun lokalizasyona, atravmatik şekilde transfer edilmesidir. Transfer sirasında kataterin uterin fundus veya duvarlara dokundurulması halinde, başarı oranlarını azalttığ 1 gösterilen çalışmalarda, uterin kontraksiyonların tetiklenmesi ile ilişkili olabileceğ vurgulanmaktadır ${ }^{7,8}$. Ayrıca yine ET başarısının arttırılması için kanla temastan kaçınılması, kullanılan transfer katateri tipi, transfer öncesi deneme transferi yapılmas1, ve transfer sonrası istirahat gibi minör değişiklikler ile ilgili çalışmalar da yapılmıştır ${ }^{9-12}$.

Embriyo transferi sırasında ultrasonografi ile monitörizasyonu, kataterinin gözlenerek ve takip edilerek ET yapılmasının standart klinik dokunma yöntemine göre başarıyı arttırdığını gösteren çalışmalar mevcuttur ${ }^{13}$. Ultrason kılavuzluğunda ET yapılacak ise; ultrasonografi transvajinal veya abdominal yol ile kullanılabilir. Transfer sırasındaultrason kullanılması iç kataterin takibine olanak sağlamakta ve endometrial kaviteye istenilen seviyeye, fundusa dokunulmadan transferin yapılmasına olanak sağlamaktadır ${ }^{14}$. Bunun yanında özellikle abdominal ultrason takibi yapılacaksa hastanın mesanesinin dolu olması gerekliliği, asistans gerekliliği, daha zaman alıcı olması gibi dezavantajları da olmasının yanında, klinik sonuçlara katkı sağlamadığını gösteren çalışmalar da mevcuttur ${ }^{15}$. Transfer sırasında ultrasonografi kullanılması ile ilgili çeşitli çalışmalar bulunmakla birlikte; çalışmaların tümünün sonucunda tutarlı bir şekilde klinik sonuçları iyileştirdiğini gösteren veri bulunmamaktadır ${ }^{16,17}$. Çalışmalar arasındaki heterojenite farklı transfer tekniklerinin, çoklu klinisyenler tarafından uygulanmasından kaynaklanıyor olabilir.

Embriyo transferi YÜT tedavilerinin başarısının arttırılması için önemli bir basamak iken, ET tekniği ile ilgili literatürde sınırlı sayıda ve farklı klinik sonuçları olan çalışmalar bulunmaktadır. IVF sikluslarının başarısı için önemli bir basamak olan ET aşaması için her klinik kendi protokollerini de gözden geçirmeli, gereken değişiklik ve iyileştirmeleri planlamalıdır. Bu amaçla çalışmamızda, ET sırasında abdominal ultrasonografi kullanılmasının, ultrasonografi kullanılmadan klinik dokunma yöntemi ile ET yapılan olguların birincil sonuç olarak; implantasyon ve klinik gebelik oranlarının karşılaştırılması hedeflenmiştir.

\section{Gereç ve Yöntem}

Çalışma Uludağ Üniversitesi Tıp Fakültesi Tüp Bebek Merkezi'nde Ocak 2017 ve Ocak 2018 tarihleri arasında çeşitli endikasyonlar ile ICSI siklusu uygulanan ve ET yapılan 93 hastanın retrospektif olarak değerlendirilmesi ile yürütüldü. Doksanüç hastanın 47'si 1. grupta, yani abdominal ultrasonografi ile ET yapilan, 46's1 ise grup 2'de yani; klinik dokunma yöntemi ile ET yapılan hastalardan oluşmaktadır.

Dahil edilme kriterleri; 18-40 yaşları arasında, BMI < $35 \mathrm{~kg} / \mathrm{m} 2$ olan, saptanan uterin patoloji olmayan, transfer gününde (5. gün) iyi kalitede 18 tek ET yap1lan, taze sikluslarda, kolay embriyo transferi yapılan hastalar (servikal manipülasyon veya katater kılavuz kullanım gerekliliği olmayan) dahil edilmiştir. Dışlanma kriterleri olarak, BMI > 35 kg/m2, donmuş ET siklusları, tanı konmuş uterin patolojisi olan, zor ET (transfer sirasinda tenekulum veya katater kilavuzu kullanılması gerekliliği) olarak kayıt edilen olgulardır.

Kontrollü ovaryan hiperstimülasyon siklusları, tüm hastalar için over rezervlerine göre değerlendirilerek, 150-450 IU arasındaki dozlarda rekombinant gonadotropin kullanılarak antagonist protokoller şeklinde uyguland1. Stimülasyonun beşinci günde başlanmak üzere hastalar sık aralıklarla, serum estradiol, progesteron düzeyleri ve seri transvajinal ultrasonografik ölçümler ile takip edildi. Transvajinal ultrasonografide dominant follikül $14 \mathrm{~mm}$ boyutuna ulaştığında, antagonist olarak subkutan Cetrorelix 0.25/gün (Cetrotide; Merck Serono) uygulanmıştır (esnek antagonist protokol). Ultrasonografik ölçümlerde ortalama 18 mm'ye ulaşan en az iki follikül ya da 17 mm'ye ulaşan en az 3 follikül belirlendiğinde, 250 mikrogram subkutan rekombinant koriogonadotropin alfa (rhCG) (Ovitrelle;Merck Serono) kullanılarak oosit matürasyonu tetiklendi. hCG uygulanma günü serum progesteron düzeyi $1.5 \mathrm{ng} / \mathrm{ml}$ 'nin üzerinde olması halinde donmuş embriyo transferi yapılması için embriyoların dondurulması önerildi. Oosit toplama işlemi (OPU) transvajinal utrasonografi eşliğinde rhCG uygulamasından 34-36 saat sonra genel anestezi altında gerçekleştirildi.

Tüm oositlere intrastoplazmik sperm injeksiyon (ICSI) işlemi uygulandı. Embriyo transferleri 5. günde iyi kalite embriyolar ile, yumuşak katater kullanılarak, standart miktarda kültür medyumu kullanılarak gerçekleştirildi.

Tüm hastaların transferleri Cook katater kullanılarak, tek klinisyen tarafından yapılmıştır. Embriyo transferi için hazırlık aşaması tüm hastalar için aynı şekilde yürütülmüştür. Hastalar litotomi pozisyonu altında spekulum ile serviks görüntülendikten sonra, servikal mukus ve sekresyonlar serum fizyolojik ile temizlene- 


\section{Embriyo Transferi Tekniklerinin Karşılaştırılması}

rek transfere hazırlanmıștır. Abdominal ultrasonografi kılavuzluğunda transfer yapılan hastaların mesanesi dolu olacak şekilde, dış kataterin yerleştirilmesi ve pozisyon verilmesi gerçekleştirilmiştir. Takiben iç kataterin yerleşim yeri olarak fundustan yaklaşı $1 \mathrm{~cm}$ mesafe kalacak şekilde tercih edildi. Ultrason kılavuzluğu hemşire yardımı ile yapıldı.

Klinik dokunma yöntemi uygulanan hastalarda ise mesanenin doluluk şartı aranmadan, ultrasonografi takibi yapılmadan, dış katater servikal internal ostan geçirildikten sonra, iç katater yavaşça ilerletilerek nazikçe fundusa dokunulduktan sonra $0.5-1 \mathrm{~cm}$ geri çekilerek ET işlemi gerçekleştirilmiştir. Transfer sonrası iç ve diş katater nazikçe geri çekildi. Transfer sonrası iç kataterin; retansiyon, kan ve mukus bulaşı açısından embriyolog tarafından kontrolü yapıldı. Tüm hastalarda ET sonrası transvajinal ultrasonografi ile hava kabarcıklarının yeri gözlenerek, hava kabarc1ğının fundusa uzaklıkları ölçüldü. Tüm hastalar transfer sonrası 1 saat istirahat ettirildi.

Luteal faz desteği için, OPU günü başlanmak üzere vaginal progesteron 2x1 (Crinone Jel \%8; Merck Serono, İsviçre) kullanıldı. Embriyo transferinden 12 gün sonrasında serum $\beta-\mathrm{hCG}$ tayini yapıldı. Luteal destek ß-hCG negatif olan hastalarda kesilirken, pozitif saptanan hastalarda 8 . gebelik haftasına kadar devam edildi. İmplantasyon tanıs1 ultrasonografide gestasyonel kese belirlenmesi ile konulurken, klinik gebelik tanısı gestasyonel kese içerisinde fetal pol ve kardiyak aktivitenin belirlenmesi ile konuldu.

Birincil sonuç olarak iki ET yöntem grubu arasında (grup 1 ve grup 2) implantasyon ve klinik gebelik oranlarının karşılaştırılması değerlendirilmiştir. İkincil sonuçlar olarak ise ET sonrası gözlenen hava kabarc1ğının fundusa olan mesafeleri değerlendirilmiştir.

\section{İstatistik Analiz}

Verinin normal dağılım gösterip göstermediği Kolmogorov-Smirnov ve Shapiro Wilk testleri ile incelendi. Normal dağılım gösteren veri için gruplar arası karş1laştırmasında bağımsız t-test kullanıldı. Tanımlayıcı istatistikler ortalama, minimum, maksimum olarak belirtildi. Normal dağılım göstermeyen veri için gruplar arası karşılaştırmasında Mann-Whitney U testi kullanıldı. Tanımlayıcı istatistikler medyan, minimum, maksimum olarak belirtildi. IVF endikasyonu, uygulanan stimülasyon protokolünün dağılımı ve başarısı ki-kare test ile gösterildi. Anlamlılık düzeyi $\mathrm{p} \leq 0.05$ olarak belirlendi. Verinin istatistiksel analizi SPSS v 23.0 istatistik paket programında yapıldı.

\section{Bulgular}

Grup 1 ve grup 2'nin klinik ve laboratuvar karakteristikleri tablo I de verilmiştir. Ortalama hasta yaşları,
BMI ve serum AMH düzeyleri gruplar arasında anlamlı farklı değildi (sırasıyla; $p=0,903, p=0,67$, $\mathrm{p}=0$,28). Toplanan oosit, matür oosit ve fertilizasyon oranlarında gruplar arasında istatistiki farklılık gözlenmedi. (sırasıly; $p=0,64, p=0,4$ ve $p=0,84$ ) (Tablo I). Hcg uygulanma günü bakılan serum estradiol ve progesteron düzeyleri gruplar arasında benzerdi (sırasıyla $p=0,79$ ve $p=0,06)$ (Tablo I).

Tablo I. Klinik ve laboratuar karakteristikleri

\begin{tabular}{|c|c|c|c|}
\hline & $\begin{array}{c}\text { Abdominal US } \\
(\mathbf{n}=\mathbf{4 7})\end{array}$ & $\begin{array}{c}\text { Klinik Dokunma } \\
(\mathbf{n}=\mathbf{4 6})\end{array}$ & $\mathbf{p}$ \\
\hline Yaş (yıl) & $32(25-39)$ & $33(22-39)$ & 0,903 \\
BMI & $24,2(17-34)$ & $24(19-36)$ & 0,67 \\
Serum AMH & $1,25(0,01-5,2)$ & $1,69(0,01-8,46)$ & 0,28 \\
hCG günü serumE2 & $373(99-752)$ & $394,5(110-891)$ & 0,79 \\
hCG günü serum P & $0,6(0,2-1,1)$ & $0,4(0,1-1,3)$ & 0,06 \\
Toplanan oosit & $9,5(1-19)$ & $10,5(1-34)$ & 0,64 \\
Matür oosit & $6(1-16)$ & $8(1-30)$ & 0,4 \\
Fertilizasyon oranı & $0,75(0,5-0,88)$ & $0,73(0,63-0,93)$ & 0,84 \\
\hline
\end{tabular}

Hastaların tedavi endikasyonları tablo II de gösterilmiştir. Transfer edilen embriyo sayıları her iki grupta anlamlı farklı değildi (her hastaya tek ET uygulandığı için). Sırasıyla implantasyon ve klinik gebelik oranları değerlendirildiğinde, gruplar arasında implantasyon ve klinik gebelik oranları için anlamlı farklılık izlenmedi $(\mathrm{p}=0,44, \mathrm{p}=0,29)$. İmplantasyon oranları grup 1 de \%42.6, grup 2 de \%34.8 iken, klinik gebelik oranlar1 siras1 ile grup 1 de \%36.2 grup 2 de \%26.1 idi (Tablo III).

Tablo II. Hastaların tedavi endikasyonları

\begin{tabular}{|cccc|}
\hline & $\begin{array}{c}\text { Abdominal } \\
\text { US } \\
(\mathrm{n}=47)\end{array}$ & $\begin{array}{c}\text { Klinik } \\
\text { Dokunma } \\
(\mathrm{n}=46)\end{array}$ & $\begin{array}{c}\text { Toplam } \\
(\mathrm{n}=93)\end{array}$ \\
Açıklanamayan & $6(\% 12.7)$ & $6(\% 13)$ & $\mathbf{1 2}(\% 12.9)$ \\
Tubal faktör & $1(\% 2.1)$ & $1(\% 2.17)$ & $\mathbf{2}(\% 2.15)$ \\
Anovulasyon & $2(\% 4.2)$ & $1(\% 2.17)$ & $\mathbf{3 ( \% 3 . 2 )}$ \\
Erkek faktör & $12(\% 25.5)$ & $15(\% 32.6)$ & $\mathbf{2 7}(\% 29.03)$ \\
Düşük over rezervi & $20(\% 42.5)$ & $19(\% 41.3)$ & $\mathbf{3 9}(\% 41.9)$ \\
Endometriozis & $6(\% 12.7)$ & $4(\% 8.6)$ & $\mathbf{1 0}(\% 10.7)$ \\
\hline
\end{tabular}

Tablo III. İmplantasyon ve klinik gebelik oranları

\begin{tabular}{|lccc|}
\hline & $\begin{array}{c}\text { Abdominal US } \\
(\mathrm{n}=47)\end{array}$ & $\begin{array}{c}\text { Klinik Dokunma } \\
(\mathrm{n}=46)\end{array}$ & $\mathrm{p}$ \\
Implantasyon & $20(\% 42.6)$ & $16(\% 34.8)$ & $\mathbf{0 , 4 4}$ \\
Klinik gebelik & $17(\% 36.2)$ & $12(\% 26.1)$ & $\mathbf{0 , 2 9}$ \\
\hline
\end{tabular}


Transfer sonrası transvajinal ultrasonografi ile kontrol edilen hava kabarcığının fundusa olan mesafeleri karşılaştırıldığında; iki grup arasında anlamlı fark gözlenmedi grup 1 ve 2 de sirasıyla; $13,4 \pm 4,23$ ve $14,4 \pm 3,91(\mathrm{p}=0,25)$ (tablo IV). Transfer sirasinda değerlendirilen endometrial kalınlık ölçümleri de gruplar arasında farklılık göstermedi $(\mathrm{p}=0,83)$ (Tablo IV).

Tablo IV. Transfer sonrası hava kabarcığının fundusa olan mesafesi, transfer sirasinda endometrial kalınlık

\begin{tabular}{|cccc|}
\hline & $\begin{array}{c}\text { Abdominal } \\
\text { US }\end{array}$ & $\begin{array}{c}\text { Klinik } \\
\text { Dokunma }\end{array}$ & $\mathbf{p}$ \\
$\begin{array}{c}\text { Hava kabarcığının fundusa } \\
\text { mesafesi(mm) }\end{array}$ & $13,4 \pm 4,23$ & $14,4 \pm 3,91$ & 0,25 \\
$\begin{array}{c}\text { Transfer günü endometrial } \\
\text { kalınlık }\end{array}$ & $10,3 \pm 1,59$ & $10,37 \pm 1,74$ & $\mathbf{0 , 8 3}$ \\
\hline
\end{tabular}

Doksanüç hastada tek gelişen ektopik gebelik grup1 (abdominal ultrasonografi ile transfer yapilan) de gözlendi.

\section{Tartışma}

$\mathrm{Bu}$ çalışmanın sonucunda; transfer sonrasında kolay olarak değerlendirilen embriyo transferlerinin abdominal ultrasonografi veya klinik dokunma yöntemi ile gerçekleştirildiğinde implantasyon ve klinik gebelik sonuçlarının anlamlı farklılık göstermediği gözlenmiştir. Çalışmada implantasyonun embriyo kalitesinden bağımsız olarak değerlendirilebilmesi için, iyi kalite embriyosu transfer edilen ve uterin patolojisi saptanmayan hastalar değerlendirildi.

Embriyo transferi ve sonrasında gerçekleşen implantasyon, IVF/ICSI tedavi sikluslarında başarıyı kısıtlayıc1 en önemli basamaklardan birisidir ve transfer başarısının arttırılabilmesi için, transfere ait; katater tipi, kataterin kanla teması, deneme transferi yapılması, transfer sonrası istirahat gibi birçok özellik ile ilgili çalışmalar yapılmıştır ${ }^{9-12}$. Tüm bu özellikler, bakıldığında ET işleminin atravmatik olma derecesi ile ilgilidir. Tedavi başarısını belirleyen, temel olarak iyi kalitede embriyonun uygun şekilde reseptif endometriuma transferidir. $\mathrm{Bu}$ nedenle transfer sirasinda ultrason rehberliğinin kullanılmasının amacı; transfer kataterinin endometrial kaviteye uterin duvarlara dokunulmadan, kontraksiyon ve kanama gibi olumsuz faktörlerden uzaklaşılarak, embriyonun doğru pozisyona yerleștirilmesi hedeflenmektedir ${ }^{7,19}$.

$\mathrm{Bu}$ amaçla ET sırasında US kullanımının hedefleri; kataterin gözlenerek, minimal travma ile endometrial kavitede uygun lokalizasyona ilerletilmesi, embriyo ejeksiyonunun gözlenmesi ve kataterin geri çekilmesi sırasında embriyoların kaviteye verilmiş olduğunun gözlenmesidir. Ultrasonografi rehberliği için transabdominal veya transvajinal ultrasonografi kullanılabilir. Standart klinik dokunma yöntemi de uzun yıllar kullanılmış, klinisyenin deneyimiyle geliştirilmiş ve birçok klinisyen tarafindan kullanılan bir transfer yöntemidir. Literatürde mevcut olan ET'nin ultrasonografi eşliğinde yapılması ve klinik dokunma yöntemi ile yapılmasını karşılaştıran çalışmaların heterojen sonuçlarının olması; taze ve donmuş embriyo transfer sikluslarının, donör oositlerin kullanılması, aynı hastanın birden fazla siklusunun dahil edilmesi gibi faktörlerden kaynaklanıyor olabilir.

Transfer sırasında ultrasonografi kullanımının klinik sonuçlar açısından yararı gösterilen çalışmalarda, ultrasonografinin kataterin takibi sırasında kolaylık sağladığ 1 ve işlemin atravmatik (kan bulaşı olmaksızın) olarak yapıldığı vurgulanmaktadır ${ }^{13}$. Bizim çalışmamızda özellikle her iki grupta da zor transferi olan hastaların değerlendirilmemiş olması, klinik dokunma ve abdominal ultrasonografi kullanılan ET'leri arasında implantasyon ve klinik gebelik sonuçlarında anlamlı fark olmamasını açıklayabilir.

Transfer sırasında uterin kontraksiyonların değerlendirildiği çalışmalar da mevcuttur. Fanchin ve arkadaşlarının prospektif olarak ET sırasında uterus kontraktilitesini değerlendirdikleri çalışmalarında; uterus kontraksiyonlarının serum progesteron seviyeleri ile ters ilişkili olduğu ve kontraksiyonların fazla izlendiği grupta klinik başarı oranlarının düştüğü gözlenmiştir ${ }^{7}$. Klinik dokunma yöntemi ile yapılan transferlerde iç katater nazikçe fundusa dokundurulduğunda uterin kontraksiyonları nasıl etkilediğine dair kontrollü bir veri bulunmamaktadır.

Literatürde mevcut çalışmalar endometrial kalınlığın transfer gününde $7 \mathrm{~mm}$ den ince olduğu taktirde gebelik oranlarının düştüğünü ve ince endometriuma sahip hastalarda implantasyonun olumsuz etkilenebileceği bildirilmektedir $^{20}$. Çalışmamızda endometrial kalınlığı ve sekretuar faz özelliklerini etkileyen önemli faktörlerden, serum estradiol ve progesteron düzeyleri iki grup arasında karşılaştırıldığında anlamlı fark gözlenmedi. Yine transfer günü değerlendirilen endometrial kalınlık ölçümleri iki grup arasında benzerdi.

Transfer işlemi sırasında embriyoların kavite içerisine bırakıldığı lokalizasyonun fundusa olan uzaklığı, embriyolar görülemeyeceği için gözlenen hava kabarcığı kullanılarak değerlendirildiğinde, klinik sonuçları etkilediğine dair veri bulunmaktadır. Embriyo transferleri sirasında ultrasonografi kullanılmasinın bir avantajı da yerleştirilen kataterin fundusa olan mesafesinin gözlenebilmesidir. Embriyonun yerleştirilme yeri ve fundus arasındaki mesafenin değerlendirildiği çalışmaların meta-analiz sonuçları 20 mm'lik mesafenin, 10 mm'lik mesafeye göre daha başarılı sonuçlar elde edildiği yönündedir ${ }^{21}$. Fundusa çok yakın yapılan transferlerin klinik gebelik oranlarını azaltırken, ekto- 


\section{Embriyo Transferi Tekniklerinin Karşılaştırılması}

pik gebelik oranlarını arttırdığı da gösterilmiştiir ${ }^{22,23}$. $\mathrm{Bu}$ açıdan da ultrasonografi eşliğinde yapılan transferlerde uterin kavitenin ve katater ucunun lokalizasyonundan emin olunarak gözlenmesinin embriyonun uygun mesafeye transferini sağlayabileceği vurgulanmaktadır. Bizim çalışmamızda iki grup arasında transferden hemen sonra transvajinal ultrasonografi yapilarak gözlenen hava kabarcığı ile fundus arasındaki mesafe ölçümlerinde anlamlı olarak fark bulunmadı. Bizim sonuçlarımız ile benzer şekilde, yakın zamanda 409 ET siklusunda transfer sonrası hava kabarcığının uterin fundusa olan mesafesi değerlendirilerek yürütülen bir çalışmada, implantasyon ile sonuçlanan transferlerde ölçülen mesafe, gebelik elde edilemeyen sikluslar ile karşılaştırıldığında anlamlı fark bulunamamıștır ${ }^{24}$. Bu noktada ET sonrası embriyonun lokalizasyonun belirteci olarak kullanılan hava kabarciklarının yer değiştirip değiştirmediği sorusu gündeme gelmektedir. Bu konu ile ilgili literatürde kesin kanaata varılmış değildir. Embriyoların $81 \%$ oranında ${ }^{25}$ bırakıldıkları lokalizasyona implante olduğunu gösteren çalışmaların yanısıra, birçok hastada transferin hemen ardından hızla yer değiştirerek sadece $11 \%$ gibi düşük bir oranda yer değiştirmediğini iddia eden çalışmalar da bulunmaktadır ${ }^{26}$. Bizim çalışma popülasyonumuzda tek ektopik gebelik olan hastanın ultrasonografi eşliğinde transferi yapılan bir hastada gözlenmesi de bu veriyi desteklemektedir. Ancak embriyo lokalizasyonu belirleyecek daha iyi bir belirteç olmadığı için günümüzde birçok çalışmada hava kabarcığ 1 görünümü değerlendirilmektedir. Her iki grup arasında fundusa olan mesafeler arasinda fark bulunmaması klinik dokunma yöntemiyle de embriyoların, ultrason altında transfer edildiği noktaya bırakabileceğini göstermektedir. Ancak bu konu ile kesin kanaate varmak için konu ile ilgili prospektif çalışmalara ihtiyaç vardır. Günümüzde klinik dokunma yöntemi ile transfer halen birçok deneyimli klinisyen tarafından tercih edilmektedir. Bu yöntemde iç kataterin yerleştirilmesi sırasında transfer noktasının belirlenmesi için kaçınılmaz olarak hafifçe de olsa fundusa dokunulma gerekliliği, uterin kontraksiyonları tetikleyebileceği için fundusa dokunulması yöntemin dezavantajı olarak vurgulanmaktadır? ${ }^{7}$ Yine kataterin ucunun takip edilememesi ve hissedilmeden katater ucunun fundusa dayanarak tubal ostiumlara doğru yönelebileceği de gösterilmiş$\operatorname{tir}^{27}$. Klinik dokunma yöntemi ile yapılan transferlerin klinisyenler arası farklılık da doğurabileceği için objektif değerlendirmesi yapılamayabilir ve farklı klinik sonuçları yansıtabilir. Ultrason kullanımının klinik dokunma yöntemine klinik başarı oranları açısından üstünlüğünün olmadığını gösteren çalışmalar, klinisyenler arası heterojenite ile açıklanabilitr ${ }^{28}$. Bizim çalı̧̧mamızda uygulanan tüm transferlerin tek klinisyen tarafından yapılmış olması daha homojen bir değerlendirmeye olanak tanımaktadır.
Embriyo transferi sırasında ultrasonografi rehberliğinden faydalanılması ile ilgili yapılan çalışmaların farklı sonuçları bildirilmiştir. Coroleu ve arkadaşları ultrasonografi kullanımının, klinik dokunma yöntemi ile karşılaştırıldığında gebelik oranlarını arttırdığını öne sürmüşlerdir $^{29}$. Bunun yanında US kullanılmasının klinik gebelik sonuçları açısından ek fayda sağlamadığını iddia eden çalışmalar da mevcuttur ${ }^{30,31}$. Transferin atravmatik olmasının başarı oranlarını arttırdığı bilinmektedir. Ancak yapılmış olan çalışmaların heterojenitesi ve özellikle zor transferler, iç kataterin ucunda kan bulaşı gözlenmesi gibi durumların sonuçları ile ilgili güvenilir veri bulunmamaktadır. Yakın zamanlı Cochrane verilerine bakıldığında ise; ultrasonografi kılavuzluğu kullanılan popülasyonda klinik dokunma yöntemine göre devam eden gebelik oranları ve canlı doğum oranları sonuçlarını olumlu etkilediği vurgulanmaktadır ${ }^{32}$. Ancak çalışmaların metodolojik heterojenitesi, sonuçların hep beraber yorumlanmasını zorlaştırmaktadır.

Transfer sırasında ultrasonografi kullanımının dezavantajları; ek asistans gerekliliği ve transabdominal prob kullanılacak ise hastanın mesanesinin dolu olmaS1 gerekliliğidir. Transfer sirasinda dolu mesane ile transfer yapılmasının işlemin konforunu değerlendiren bir çalışmada, mesane doluluğunun işlem konforunu olumsuz etkilediği vurgulanmıştır ${ }^{33}$. Yine özellikle cilt altı yağ dokusu kalın olan ve obez hastalarda abdominal ultrasonografi kılavuzluğu efektif olarak fayda sağlamayabiliir ${ }^{34}$. Ayrıca abdominal ultrasonografi kullanımı için hastanın mesanesinin dolu olması, antevert uterusu olan hastalarda uteroservikal açının düzleşmesinde katkı sağlayarak transfer sırasında kolaylık sağladığı gibi, retrovert uterusu olan hastalarda endometrial kavitenin gözlenmesini uterus probdan uzaklaştıracağı için daha da zor hale getirebilir. Şimdiye kadar transfer sirasinda ultrasonografi kullanılmasının dezavantajları, ek zaman, ekipman ve personel gerekliliği gibi konularla ilgili yapılmış çalışma bulunmamaktadır.

Çalışmanın retrospektif olması limitasyonları arasındadır. Ayrıca kolay transfer yapılan hastaların karşılaştırılmış olması, zor transfer olarak değerlendirilen, servikal manipülasyon gerekliliği olan ve kataterde kan bulaşı gözlenen hastalarda değişkenlerin hesab edilememesi bu hastalarda özellikle transfer tekniği ile ilgili yeterli veri bulunmamaktadır.

Çalışmamızda kolay ET olarak değerlendirilen ET sırasında US kullanılan ve klinik dokunma yöntemi ile transferi yapılan hastaların implantasyon ve klinik gebelik sonuçları arasında istatistiki anlamlı fark bulunmamıştır. Ultrasonografi eşliğinde transfer yapılması bazı alt grup hastalarda özellikle fayda sağlayabilir. İstatistiki tip II (beta) hatalardan kaçınmak için daha geniş vaka serilerinde prospektif olarak çalışılması gerekmektedir. 


\section{Kasapoğlu, ark.}

\section{Kaynaklar}

1. Blake DA, Farquhar CM, Johnson N, Proctor M. Cleavage stage versus blastocyst stage embryo transfer in assisted conception. Cochrane Database Syst Rev 2007:CD002118.

2. Lessey BA. Assessment of endometrial receptivity. Fertil steri 2011; 96: 522-9.

3. Polanski LT, Barbosa MA, Martins WP, et al. Interventions to improve reproductive outcomes in women with elevated natural killer cells undergoing assisted reproduction techniques: a systematic review of literature. Hum Reprod 2014; 29: 65-75.

4. Phillips JA, MartinsWP, Nastri CO,Raine-Fenning NJ.Difficult embryo transfers or blood on catheter and assisted reproductive outcomes: a systematic review and meta-analysis. Eur J Obstet Gynecol Reprod Biol 2013; 168: 121-8.

5. Achache H, Revel A. Endometrial receptivity markers, the journey to successful embryo implantation. Hum Reprod Update 2006;12:731-46.

6. Teixeira DM, Dassuncao LA, Vieira CV, et al. Ultrasound guidance during embryo transfer: a systematic review and meta-analysis of randomized controlled trials. Ultrasound Obstet Gynecol 2015;45:139-48.

7. Fanchin R, Righini C, Olivennes F, Taylor S, de Ziegler D, Frydman R. Uterine contractions at the time of embryo transfer alter pregnancy rates after invitro fertilization. Hum Reprod 1998;13:1968-74.

8. Mansour R, Aboulghar M. Optimizing the embryo transfer technique. Hum Reprod 2002;17:1149-53.

9. Alvero R, Hearns-Stokes RM, Catherino WH, Leondires MP Segars $\mathrm{JH}$. The presence of blood in the transfer catheter negatively influences outcome at embryo transfer. Hum Reprod 2003; 18: 1848-52.

10. Van Weering HG, Schats R, McDonnell J, Vink JM, Vermeiden JP, Hompes PG. The impact of the embryo transfer catheter on the pregnancy rate in IVF. Hum Reprod 2002; 17: 666-70.

11. Knutzen V, Stratton CJ, Sher G, McNamee PI, Huang TT, Soto-Albors C. Mock embryo transfer in early luteal phase, the cycle before in vitro fertilization and embryo transfer: a descriptive study. Fertil Steril 1992; 57: 156-62.

12. Li B, Zhou H, Li W. Bed rest after embryo transfer. Eur J Obstet Gynecol Reprod Biol 2011; 155: 125-8.

13. Brown J, Buckingham K, Abou-Setta AM, Buckett W. Ultrasound versus 'clinical touch' for catheter guidance during embryo transfer in women. Cochrane Database Syst Rev 2010:CD006107.

14. Lorusso F, Depalo R, Bettocchi S, Vacca M, Vimercati A, Selvaggi L. Outcome of in vitro fertilization after transabdominal ultrasound-assisted embryo transfer with a full or empty bladder. Fertil Steril 2005; 84: 1046-8.

15. De Camargo Martins AM, Baruffi RL, Mauri AL,et al. Ultrasound guidance is not necessary during easy embryo transfers. $\mathrm{J}$ Assist Reprod Genet 2004; 21: 421-5.

16. Woolcott R, Stanger J: Potentially important variables identified by transvaginal ultrasound-guided embryo transfer. Hum Reprod 1997;12:963-6

17. Kan A, Abadalla H, Gafar A: Embryo transfer: Ultrasoundguided versus clinical touch. Hum Reprod 1999;14:125961 .
18. Racowsky C, Vernon M, Mayer J, et al. Standardization of grading embryo morphology. J Assist Reprod Genet 2010;27: 437-9.

19. Lesny, P., Killick, S.R., Tetlow, R.L., Robinson, J. and Maguiness, S.D. Embryo transfer can we learn anything new from the observation of junctional zone contractions? Hum. Reprod. 1998; 13, 1540-6.

20. J. F. Smith, T. J. Walsh, A. W. Shindel et al., "Sexual, marital, and social impact of a man's perceived infertility diagnosis," The Journal of Sexual Medicine, 2009; 6: 2505-15.

21. Abou-Setta AM. What is the best site for embryo deposition? A systematic review and meta-analysis using direct and adjusted indirect comparisons. Reprod Biomed Online 2007;14:611-9.

22. Pope CD, Cook EK, Arny M, Novak A, Grow DR. Influence of embryo transfer depth on in vitrofertilization and embryo transfer outcomes. Fertil Steril 2004;81:51-8

23. Nazari A, AskariHA, Check JH, O’Shaughnessy A. Embryo transfer technique as a cause of ectopic pregnancy in in vitro fertilization. Fertil Steril 1993;60:919-21.

24. Kovacs P, Sajgo A, Rarosi F, Kaali SG. Does it really matter how far from the fundus embryos are transferred? Eur J Obstet Gynecol Reprod Biol 2012, 162: 62-6.

25. Baba K, Ishihara O, Hayashi N, Saitoh M, Taya J, Kinoshita K. Where does the embryo implant after embryo transfer in humans. Fertil Steril 2000;73:123-5.

26. Confino E, Zhang J, Risquez F. Air bubble migration is a random event post embryo transfer. J Assist Reprod Genet 2007;24:223-6.

27. Woolcott R, Stanger J. Potentially important variables identified by transvaginal ultrasound-guided embryo transfer, Hum Reprod 1997;12(5):963-6

28. Anice Maria Vieira de Camargo Martins, Ricardo L. R. Baruffi, Ana L. Mauri, et al. Ultrasound Guidance Is Not Necessary During Easy Embryo Transfers. Journal of Assisted Reproduction and Genetics 2004; 21(12): 421-5.

29. Coroleu, B., Barri, P.N., Carreras, O., Martinez, F., et al. The influence of the depth of embryo replacement into the uterine cavity on implantation rates after IVF: a controlled, ultrasoundguided study. Hum Reprod 2002; 17, 341-6.

30. Al-Shawaf T, Dave R, Harper J, Linehan D, Riley P, Craft I: Transfer of embryos into the uterus: how much do technical factors affect pregnancy rates? J Assist Reprod Genet 1993;10:31- 6 .

31. Woolcott R, Stanger J: Ultrasound tracking of the movement of embryo-associated air bubbles on standing after transfer. Hum Reprod 1998;13:2107-9.

32. Brown J, Buckingham K, Abou-Setta AM, Buckett W. Ultrasound versus ‘clinical touch' for catheter guidance during embryo transfer in women. Cochrane Database Syst Rev 2016.

33. Bodri D, Colodr_on M, García D, Obradors A, Vernaeve V, Coll O. Transvaginal versus transabdominal ultrasound guidance for embryo transfer in donor oocyte recipients: a randomized clinical trial. Fertil Steril 2011;95:2263-8.

34. Paladini D. Sonography in obese and overweight pregnant women: clinical, medicolegal and technical issues. Ultrasound Obstet Gynecol 2009; 33:720-9. 